
and empirical results

\title{
Abstract
}

\section{A collaborative interest model of relational coordination and empirical results}

Coordination, cooperation and the use of power to effect exchange in business markets and distribution channels have long been studied in marketing (Anderson and Narus, 1986; Brown, 1979; Gaski, 1984; Rosenberg and Stern, 1971; Wilkinson, 1973; Wilson and Nielson, 2000). While coordination is achieved in many ways, in an abstract sense, all methods are a combination of three high order mechanisms: market forces, hierarchical control and relational coordination (Bonoma, 1976; Bradach and Eccles, 1989; Weitz and Jap, 1995). Relational coordination, where at least two firms work collectively to realize outcomes that cannot be achieved alone, remains poorly understood. This is partly explained by the lack of dyadic studies of firms in business relationships (cf. Bonoma et al., 1978; Håkansson, 1982). However, developments in the industrial marketing and purchasing (IMP) group's interaction and network framework (Ford, 1990; Håkansson, 1982; Håkansson and Snehota, 1995) and the literature on multilevel analysis in

* Corresponding author. Tel.: +61-8-8303-3103; fax: +61-8-83034368 .

E-mail address: chris.medlin@adelaide.edu.au (C.J. Medlin).

organizations (cf. Morgeson and Hofman, 1999; Rousseau, 1985), which both allow for differences in viewpoint, may lead to means of analysing dyads. Nevertheless, it would be inefficient to conduct dyadic studies prior to determining the constructs associated with relational coordination.

This paper proposes and examines empirically a collaborative interest model (CIM) of relational coordination that embeds relational constructs within the interaction and network context developed by the IMP group (Ford, 1990; Håkansson, 1982; Håkansson and Snehota, 1995). The CIM contributes to the literature by providing a theoretically sound means of examining relational coordination mechanisms that arise from the collective interests of firms in relationships.

The remainder of the paper is structured in the following manner. First, the IMP interaction and network framework is presented, with attention directed to different levels of analysis. Second, an integration of the IMP framework (Håkansson and Snehota, 1995), relational coordination constructs (Wilson, 1995) and Macneil's (1974, 1978, $1980,1983,1985)$ relational norms is undertaken. Norms are defined as "patterns of accepted and expected sentiments and behaviour that are shared by members of an exchange system and have the force of social obligation or pressure" (Gundlach et al., 1995, p. 84). As regulators of 
63 behaviour, norms would appear to offer a path to relational 64 coordination. Indeed, it is established that different sets of 65 norms are apparent in market, hierarchical and relational 66 coordination contexts (cf. Achrol, 1997). Third, a CIM that 67 explains relationship performance is developed. This model 68 incorporates levels of analysis and, in so doing, provides a 69 context for relational coordination constructs. Fourth, an 70 empirical study aimed at testing the model is described. 71 Finally, results are presented and their implications for 72 future research are discussed.

\section{The interaction and network context of relational coordination}

Business relationships do not develop in a vacuum; rather they operate between firms working in industries, which are embedded within a social fabric. The interaction and network theory of the IMP group (Håkansson, 1982; Håkansson and Snehota, 1995) describes three levels of analysis: firms, relationships and networks, as well as their associated interactions. Thus, firms are composed of actors, resources and activities; relationships are composed of actor bonds, resource ties and activity links; and networks are composed of an actor web, resource constellation and activity pattern (Håkansson and Snehota, 1995). In addition, the IMP framework conceptualises three types of interaction: those within business relationships, those between the firms and the relationship and finally, interactions between the relationship and the wider networks (cf. Håkansson and Snehota, 1995).

Thus, the IMP framework explains complexity by regarding relationships as the intervening construct between firms and networks. This has the advantage of relying upon a socially symbolic construct (i.e., a relationship) and interaction between levels of analysis to explain relationship behaviour (i.e., interaction between firms in a relationship). Thus, and in conjunction with multilevel organizational literature (cf. Morgeson and Hofman, 1999; Rousseau, 1985), the IMP framework offers a means to investigate the relational coordination process, since functional relationships between constructs at one level have implications at higher and lower levels of aggregation (Chan, 1998; Håkansson and Snehota, 1995; Morgeson and Hofman, 1999). For example, in the IMP framework, business relationships exist as interaction across three levels of organization: (i) the strategies of two firms acting as inputs, (ii) coordination processes at the relationship level, and finally (iii) the purpose of the relationship being achieved at the network level of organization. That is, relationships exist according to a logic drawn from the broader network (Håkansson and Snehota, 1995) and it is this equifinality that drives development of relational coordination.

However, research on relational coordination faces a number of interrelated problems, such as the number of levels of analysis (Rousseau, 1985), socialization of con- structs (Zaheer et al., 1998), a multitude of constructs and similarities of definition (Wilson, 1995). These issues are complex, but the different levels of analysis suggested by the IMP literature provide a means to begin dealing with these matters. The next section integrates the IMP, relational coordination constructs and relation norms, while simultaneously considering these issues.

3. Actor bonds, relational coordination constructs and relational norms

Within the IMP framework it is the nature of actor bonds at the relationship level that partially determines acceptable responses to changes in activity links and resource ties (Håkansson and Snehota, 1995; Medlin and Quester, 1999). Briefly, actor bonds, actor intentions and their reciprocal 'conditioning' shape a firm's understanding of environmental events or of any change arising from the firms in the relationship. Furthermore, this interpretation of events informs the optimal strategy and tactics available to the firm and the relationship in response to any change. Thus, the nature of the present relationship emerges from interaction between past actor bonds and firm intentions as well as consideration of future orientations of these aspects of relationships.

However, Håkansson and Snehota (1995) identify only trust and commitment as important attributes of actor bonds. Yet, trust and commitment are but two of a range of norms that may exist within actor bonds. For instance, Macneil (1974, 1978, 1980, 1981, 1983, 1985) suggested a range of relational norms required to maintain long-term exchange in a relationship context. However, there are two problems that must be explained before these literatures may be integrated: (i) organization level of relational norms and (ii) the linkage between relational coordination processes, relational norms and actor bonds.

The point of departure for Macneil $(1974,1978)$ is the importance of the future in conditioning current contractual relationships. Contracts can never codify all future contingencies. Thus, relationship parties must fill contractual gaps with relational norms to assure continuance (Macneil, 1974, 1978). Macneil (1980) proposes three classes of norms. The first class consists of 10 common norms of contract that are evident within and across all of society. (These common norms have been enumerated by Dwyer et al. (1987).). This class of generic norms are transformed depending on the nature of the contract (i.e., discrete or continuing) into two classes of specific norms (i.e., market or relational). Macneil (1980, 1983) proposed that relational norms develop from the intensification of four common norms and the fading of the remaining six. The four relational norms based on common norms include: solidarity, harmonisation of relational conflict, role integrity and propriety of means. In addition, other relational norms, not based on common norms, also develop within a relationship (Macneil, 1983). 
169 These supplementary relational norms are mutuality and

170 open communication.

171 That relational norms develop within a relationship, 172 while the norms for discrete contracts fit market situations 173 deserves close attention for there is ambiguity with regard to 174 levels of aggregation. That is, the relationship parties build 175 relational norms, which are likely to be based on culturally 176 embedded ideals yet are partially separated from societal 177 norms. On the other hand, market norms also exist and are 178 socially constructed in a wider environment (i.e., the mar179 ket). That relational norms develop within a relationship 180 clearly places them at the same level of aggregation as actor 181 bonds, hence these two sets of constructs may be considered 182 as of equivalent analytic level. This leaves the problem of 183 how actor bonds (and relational norms) and firm level 184 coordination processes relate to each other within the IMP 185 framework.

186 The solution proposed here is based on Morgeson and 187 Hofman (1999) and the earlier work of Giddens (1979), 188 where structure exists as a "duality," which is at once a 189 context that results from interaction between parties and the 190 medium for that very same process of interaction. This 191 duality of structure, as context and medium, allows one to 192 conceive of actor bonds as an outcome of both parties' view 193 of an interaction, while at the same time this structure 194 conditions the interaction and also acts as the medium for 195 the interfirm coordination process.
While actor bonds are relationship level constructs, they can only be interpreted as such from an individual level and based upon a generalisation about the nature of interfirm interaction. Once individuals in the partnering firms make this generalisation, actor bonds are available to shape the way that individuals and thus firms, through significant social actors, conduct the relationship coordination process: with this process characterized by the nature of communication, acquiescence, flexibility and conflict, among many dimensions identified in the literature (Wilson, 1995). This conceptualization of actor bonds is similar to Wilson and Nielson's (2000) global cooperation construct, which is formed as a result of a single respondent interpreting the interaction with a partner firm from both sides, with the resulting observation leading to trust, strategic benefits and relationship continuity. Furthermore, defining actor bonds in this way is important for it avoids the criticism of socialization for firm level constructs (cf. Zaheer and Venkatraman, 1995) by recognizing that social and psychological processes underwrite all resource decisions and responses to economic change within business relationships, while avoiding the inference that firms are human entities. Thus, all interpretation of events proceeds through the lenses of social symbolism (cf. Elias, 1991).

The equating of relational norms and actor bonds as relationship level constructs inevitably requires resolution of the similarities of definition that plague business research.
196

197

198

199

200

201

202

203

204

205

206

207

208

209

210

211

212

213

214

215

216

217

218

219

220

221

222

t1.1 Table 1

t1.2 Comparison of constructs

Actor bonds (Håkansson

Macneils' relational norms

t1.3 and Snehota, 1995) (Macneil, 1980)

$\mathrm{t} 1.4$

$\mathrm{t} 1.5$

Commitment "tendency to persist with courses of action" in the development of

"mutual pictures"

(Håkansson and Snehota, 1995, p. 198) None

$\mathrm{t} 1.6$

None

$\mathrm{t} 1.7$

None

$\mathrm{t} 1.8$ $\mathrm{t} 1.9$

None

\section{Trust mutual trust}

(Håkansson and

Snehota, 1995)

Mutuality-degree to which partners focus on the benefits of the relationship as a whole over the long-term, rather than monitoring individual transactions for fairness (Kaufmann and Stern, 1988)

Solidarity-a common belief of future interdependence (Macneil, 1980)

Role integrity the complexity with which activities are divided amongst the parties in a relationship

(Macneil, 1980)

Propriety of means-multiple paths available to achieve any outcome when strong relationships develop (Macneil, 1980)

Open communication communication is "extensive, deep, ..., informal" (Macneil, 1978, p. 902)

Conflict Harmonization

"restraint of power"

(Macneil, 1981)
Interfirm coordination Study constructs

dimensions

Trust- "confidence in an

exchange partner's

reliability and integrity"

(Morgan and Hunt, 1994,

p. 23)

Commitment- “on-going

relationship with another is so important as to warrant maximum efforts at maintaining it" (Morgan and Hunt, 1994, p. 23)

None

Trust "confidence in an

exchange partner's reliability and integrity" (Morgan and Hunt, 1994, p. 23)

Commitment "on-going relationship with another is so important as to warrant maximum efforts at maintaining it" (Morgan and Hunt, 1994, p. 23)

Role integrity dimensions of roles (Kaufmann and Stern, 1988)

Flexibility-"expectations of willingness to make adaptations" (Heide and John, 1992, p. 35)

Flexibility "expectations of willingness to make adaptations" (Heide and John, 1992, p. 35)

Information exchange - expectation that each party will pro-actively provide information to the partner (Heide and John, 1992) Influence, use of power (Boyle et al., 1992; Frazier, 1999; Gaski, 1986)
Communication expectation that each party will pro-actively provide information to the partner (Heide and John, 1992) Conflict harmonization "restraint of power” (Macneil, 1981) 
223 Table 1 provides an overview of constructs by literature area 224 and indicates their similarities, and displays the constructs 225 used in this study. The naming of constructs in this study 226 follows first the IMP framework, and then the more 227 developed coordination process literature and finally the 228 relational norms perspective. The only exception is 'conflict 229 harmonization' that represents more than use of power and 230 influence by focusing on a proactive reduction of conflict 231 (Macneil, 1980).

232 The next section develops a composite model across 233 three levels of organization so that an appropriate setting is 234 used to examine potential relational coordination constructs 235 available for defining actor bonds.

\section{A CIM of relational coordination}

237 The relational coordination process exists within a spe238 cific business context, where firms decide to work together 239 to achieve results that neither could individually realize. 240 These results have meaning at a firm level, but their true 241 significance from a relationship perspective is at a network 242 level, where relationship strategy has a main consequence. 243 The other consequence, which is ignored here, is at the firm 244 level. Hence, in this study, performance must be measured 245 with reference to the network and with regard to competing 246 networks. While Lumpkin and Dess (1996) point out that 247 performance has a number of dimensions, in this study 248 "relationship performance" as an output relative to the 249 network does not need to be examined as a multidimen250 sional construct. As this study seeks to uncover the rela251 tional constructs involved in relationship performance, it is 252 enough to focus on economic outcomes, which in the long253 term subsume strategic outcomes. Thus, relationship per254 formance within a network is an output of interaction 255 between two other levels of aggregation (firms and rela256 tionship) and as such is a higher order unidimensional 257 construct. This is an important insight, for the reciprocal 258 conditioning effects between relational coordination con- structs may be examined with reference to a variable that more correctly represents the purpose of strategic business relationships and so offers a means to integrate constructs within and across levels (cf. Morgeson and Hofman, 1999).

Firms enter into relationships with suppliers, customers and significant partner organizations based on strategic plans (Axelsson and Easton, 1992; Borys and Jemison, 1989; Ford, 1990). These strategic plans represent a collective interest on the part of firms, founded on the belief that long-term coordinated action with another firm is important. At the heart of this strategy is an interest in maintaining future exchange based on expected net gains (Dwyer et al., 1987; Ganesan, 1994). In addition, a firm's past experience with acting collectively will also provide knowledge and skills that will shape the coordination process between the firms (Wilson, 1995).

Importantly, this mutual alignment of motivation at the firm level involves the recognition of the role played by both self-interest and collective interest, which coexist in relationships (cf Young and Wilkinson, 1997). The role of self-interest, in the form of economic goals at the firm level, is evident in the need for individual rewards as a basis for a motivation to interact; while collective interest is partially displayed by the way the other party mediates the collective rewards. The inclusion of self-interest is an important element of this model, for the aggregated nature of relationships necessarily subsumes individual actor constructs.

At the relationship level, firms interact and create actor bonds, whose overarching relationship level of interpretation provides for acceptable variations in the coordination response that firms can make to environmental change and/ or change within the participating firms (Medlin and Quester, 1999). Greater integration of actor bonds across the parties implies a more complex relationship and the potential to choose from a wider set of possible responses so that a firm and a relationship have the potential to be more successful.

Fig. 1 presents the hypothesised relationships between the main constructs, based on the discussion above and the

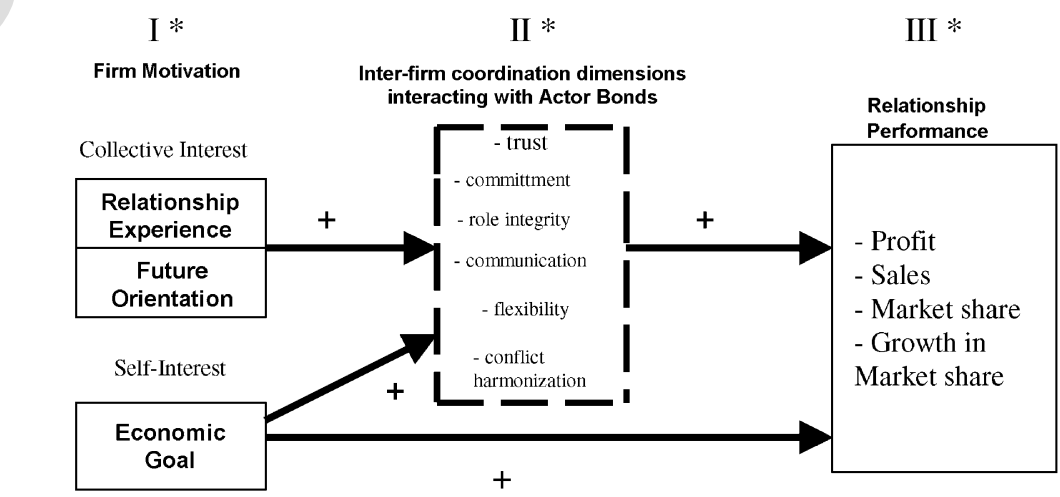

* I = firm level, II = inter-firm dimensions inside box to explain Actor Bonds at relationship level, III = network level

Fig. 1. Collaborative interest model of relational coordination. 
298 theoretical underpinning of relationship structure, purpose 299 and levels of analysis of the IMP framework. The inter300 actions between specific coordination and actor bond con301 structs are not discussed here in detail, for only some may 302 be required in the pursuit of relationship performance.

\section{5. Method}

304 The methodology chosen to test this model involves a 305 survey of computer software firms engaged in the export/ 306 import of business software using principal/distributor or 307 principal/agent relationships. This specific industry segment 308 was chosen for several reasons. First, the business software 309 industry reflects a network structure because the product 310 requires close long-term relationships between principal and 311 distributor/agent to manage continuous change.

Second, our study, by focusing on one industry, controlled for the effect of industry culture on the study. This is consistent with the approach undertaken in previous business relationship studies such as the automobile tyre sector (Morgan and Hunt, 1994) or health care professionals (Kalafatis and Miller, 1997). Consequently, and since they operate in a similar industry environment, these firms are more likely to reveal relative strengths/weaknesses in relation to their competitors than would firms operating in a number of different industrial sectors where differing environmental factors would require different skills in order to perform.

Third, the problem of copyright breaches and piracy in the computer software industry means that principals generally seek to establish long-term relationships with known and trusted partners. Opportunistic and short-term strategies would be highly discouraged in a situation where providing the software immediately exposes the principal to the risk of intellectual property theft. Finally and very pragmatically, the relative small size of this industry allowed the researchers to achieve a reasonable degree of representativeness by enabling a census whereby each known actor of the industry is invited to participate in the study.

In this study, both sides of the principal/distributor relationship have been included, so that a second study at the dyad level might be conducted. However, the present study only operationalizes potential actor bond constructs from the perspective of an individual firm. In an initial step, a comprehensive list of exporting firms (312 Australian, 175 New Zealand) was obtained from a commercial database. A one-page facsimile survey was then used to identify those firms involved in any type of distribution arrangement, ranging from gentleman's agreement to legal arrangements.

This process resulted in a final list of 128 Australian and New Zealand firms identified as having relationships with Malaysian or Singaporean distributor/agent firms. English is the business language of Malaysian and Singaporean firms. Each firm in this sample was then contacted and the person responsible for managing the Malaysian/Singapore relation- ships was identified. The ability of the manager to be a key informant (Campbell, 1955) was established and a qualification process was applied to collectively nominate the partner firm and respondent in the other country. Finally, surveys were mailed to the key informants in both firms. Eventually, information on 83 relationships (from 45 principals and 38 agents/distributors, incorporating 34 dyads and 15 unmatched firms) were collected and analysed, representing a response rate of $32 \%$. To achieve this response rate, continual personal reminders and interviews were required over a 5-month period. The main reason for initial nonresponse was given as lack of time, with six firms refusing to participate because of either confidentiality or policy. There were no discernible differences between early and late responses.

\subsection{Method of analysis}

Analysis was conducted using structural equation modelling (SEM) for a number of reasons. First, SEM provides a method to develop parsimonious models with small samples. Often small samples have high levels of multicollinearity, so that models do not converge and valid models are often rejected. Sample size can also bias measures of predictivity. In particular, the "standard" chi-square measure of fit between observed and estimated covariance structures is optimistic when the sample is small. However, SEM allows a parsimonious solution to be sought by considering models comprising only highly significant relationships and by checking complementary goodness-of-fit measures, which adjust for sample size and model complexity. In this study, Steiger's (1989) root mean square error of approximation (RMSEA), a population-based index that is relatively insensitive to small sample size (Loehlin, 1992), was used to determine goodness-of-fit. Steiger considers any value less than .1 as a "good" fit and less than .05 as "very good."

A second reason for choice of SEM was that violation of the hypothesis of a multinormal distribution of the variables might also bias the confidence interval of the parameters and the consecutive chi-square measures. Hence, the maximum likelihood estimator was used, since it has proven to be resistant against moderate to strong departures from multinormality. In addition, interval variables (nine-point scale) were used and all variables were checked for multinormality using Prelis tests of multivariate skewness and kurtosis (Jöreskog and Sörbom, 1996).

SEM also allows use of a stepwise strategy to progressively simplify from a complex to a parsimonious model (Kaplan, 1990). This process involves using modification indexes and expected parameter change statistics, in conjunction with substantive theory, to assess a number of embedded models in decreasing order of complexity. This process results in the removal of less important theoretical relationships so that a more parsimonious model is achieved, while retaining a reasonable fit. The process is 
t2.1 Table 2

t2.2 Global measurement model

t2.3 Construct

t2.

$\mathrm{t} 2.5$

t2.6

$\mathrm{t} 2.7$

t2.8

t2.9

t2.10 Flexibility

$\mathrm{t} 2.11$

t2.12 Role integrity

$\mathrm{t} 2.13$

$\mathrm{t} 2.14$

t2.15 Commitment

$\mathrm{t} 2.16$

t2.17 Trust

$\mathrm{t} 2.18$

$\mathrm{t} 2.19$

t2.20 Relationship performance

$\mathrm{t} 2.21$
Relationship experience

Future orientation

Economic goal (1)

\begin{tabular}{llrl} 
Item & $\lambda$ & $t$-value & $R^{2}$ \\
1 & 0.90 & 7.00 & .81 \\
2 & 0.60 & 5.05 & .36 \\
1 & 0.89 & 7.20 & .80 \\
2 & 0.76 & 7.56 & .58 \\
1 & 0.95 & 9.69 & .90 \\
2 & 0.90 & 9.02 & .80 \\
1 & 0.97 & 11.18 & .94 \\
2 & 0.96 & 10.93 & .91 \\
1 & 0.94 & 11.02 & .89 \\
2 & 0.79 & 8.33 & .62 \\
3 & 0.90 & 10.21 & .81 \\
1 & 0.92 & 10.07 & .84 \\
2 & 0.85 & 9.07 & .73 \\
1 & 0.90 & 10.23 & .81 \\
2 & 0.91 & 10.54 & .84 \\
3 & 0.85 & 9.40 & .72 \\
1 & 0.95 & 11.15 & .90 \\
2 & 0.99 & 11.91 & .97 \\
\hline
\end{tabular}

Table 4

Correlation matrix of final indicators

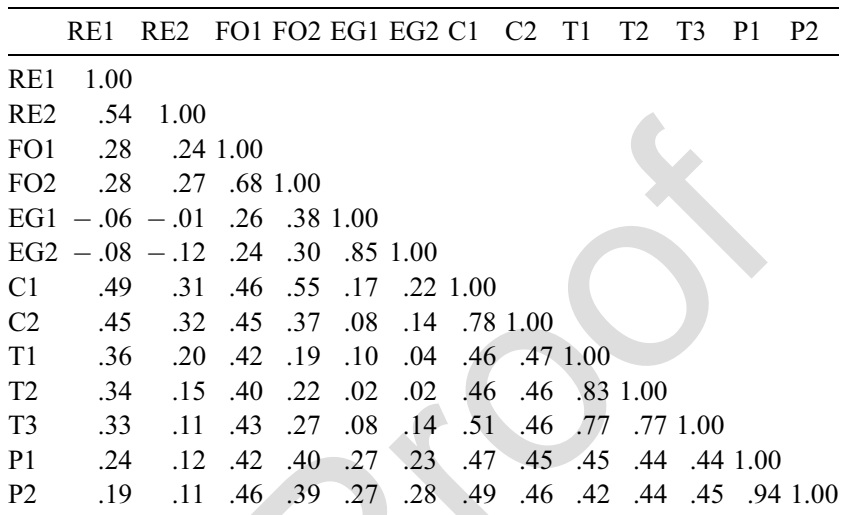

stopped when a goodness-of-fit criterion, corrected for complexity, does not improve substantially when further simplification is considered. The Expected Cross-Validation

t3.1 Table 3

t3.2 Constructs, sources and scales

t3.3 Construct (source)

\begin{tabular}{ll} 
& $\begin{array}{l}\text { Number } \\
\text { of items }\end{array}$ \\
\cline { 2 - 2 } & 2
\end{tabular}

$$
\text { t3.4 (developed for present study) }
$$

$\mathrm{t} 3.5$

$$
\begin{array}{lc}
\text { Future orientation } \\
\text { t3.6 (Ganesan, 1994) }
\end{array}
$$

t3.7

\section{$\mathrm{t} 3.8$}

t3.9 Flexibility

t3.10 (Heide and John, 1992)

t3.11

$\mathrm{t} 3.12$

\section{Role integrity}

\section{t3.13 (Kaufmann and Stern, 1988)}

$\mathrm{t} 3.14$ t3.15

t3.18 Commitment

t3.19 (Holm et al., 1996)

$\mathrm{t} 3.20$

t3.21

t3.22 Trust

$\mathrm{t} 3.23$

t3.24

$\mathrm{t} 3.25$

$\mathrm{t} 3.26$

$\mathrm{t} 3.27$

Relationship performance

$\mathrm{t} 3.28$
(Aulakh et al., 1997;

(Morgan and Hunt, 1994)

Holm et al., 1996)
Scales * denotes the indicators used in the final model

* 1. In our firm's past relationships, the parties have treated problems as joint rather than individual responsibilities (strongly agree-strongly disagree).

* 2. Our firm prefers to work out solutions to problems that benefit the relationship as a whole, and not only the individual parties.

* 1 . We believe that over the long term our relationship with this partner will be profitable.

* 2. Maintaining a long-term relationship with this partner is important to our firm. For each goal indicate its relative importance to your firm's overall strategy with regard to the focus relationship: profit, sales, sales growth, * market share, * market share growth (extremely important-not important).

* 1. Flexibility in response to requests for changes is a characteristic of this relationship.

$* 2$. The parties expect to make adjustments in the on-going relationship.

3. The parties expect to be able to make adjustments to cope with changing circumstances.

4. When an unexpected situation arises, the parties prefer to work out a new deal, rather than hold each other to the original terms.

1. The exchange relationship with the partner firm has created a complex web of tasks related to our commercial activity.

*2. The exchange relationship with the partner firm has created a complex web of interactions over all kinds of issues.

*3. The exchange relationship with the other party is extremely complicated.

*4. The exchange relationship with the partner firm has created a complex web of interactions between us.

5. The exchange relationship with the partner firm has created a complex web of tasks that extend beyond our direct commercial.

* 1 . Our firm and the partner firm are very committed to each other.

*2. The partner firm is very committed to our firm.

3. The partner firm is willing to invest time and money in developing this relationship.

4. The partner firm appears more concerned with their own outcomes in this relationship.

1. At times in this relationship the other party cannot be trusted.

2. In this relationship, the other party can be counted on to do what is right.

* 3. The other party is truly sincere in their promises.

* 4. The other party can be completely trusted to meet their obligations to the partnership.

*5. Our partner is perfectly credible.

6. The other party can be counted on to help this firm if the need arises.

Relative to your firm's expectations in the focus market what has been the performance of the interfirm relation on the following dimensions: overall performance, profit, sales, sales growth, * market share, * market share growth (extremely strong-not strong). 
t5.1 Table 5

t5.2 Structural model results

$\mathrm{t} 5.3$

t5.4 Relationship experience

$\mathrm{t} 5.5$

t5.6 Future orientation

$\mathrm{t} 5.7$

t5.8 Economic goal

t5.9

t5.10 Commitment

$\mathrm{t} 5.11$

t5.12 Trust

t5.13

$\mathrm{t} 5.14$

t5.15 Performance

$\mathrm{t} 5.16$

Interfactor correlations are as follows: relationship experience and future orientation: $\phi=.39(t=3.21)$; relationship experience and economic goal: $\phi=-.08(t=-0.61)$; future orientation and economic goal: $\phi=.41$ $\mathrm{t} 5.17(t=3.81)$.

409 Index (ECVI) used in this analysis is based on Akaike's 410 (1987) seminal information criterion (Akaike Information 411 Criterion-AIC), which accounts for sample size (Akiake, 412 1987; Bozdogan, 1987). Information theory based criteria 413 are measures of fit adjusted for complexity and so they are 414 useful tools for comparing embedded models.

415 Prior to employing SEM, confirmatory factor analyses 416 were conducted using a Pearson correlation matrix, by 417 considering jointly the indicators corresponding to the same 418 causal level. This led to three measurement analyses and the 419 resulting latent variables were then analysed together within 420 the global measurement model. Conforming to the concern 421 for controlling sample size biases, all of the selected items 422 have large $t$ values (see Table 2). Following these analyses, 423 the constructs of "communication" and "conflict harmon424 ization" were found unadmissible and, consequently, 425 removed. All other variables, including relationship per426 formance, exhibited strong unidimensionality. Table 3 427 presents the final constructs, the number of items and their 428 source. While the chi-square was unreliable for this sample 429 size (145.36 with 107 degrees of freedom, $P=.0081$ ), this value could be enhanced significantly by removing the role integrity construct (which proved necessary in the final causal model). However, the fit measure was acceptable (RMSEA=.066). Table 4 provides the observed correlation matrix of the indicators.

One consequence of the reduced sample size was that the number of significant indicators reflecting a latent variable was often reduced to two. This is not a fundamental problem, given the exploratory nature of this study, since the remaining items continue to reflect the unidimensionality of the original scales and would be the cores of larger multiitem scales to be used in future research.

\section{Results}

Following Kaplan's (1990) stepwise process, the constructs for Role Integrity and Flexibility were removed from analysis. The RMSEA of the final model is .049 with a $90 \%$ confidence interval extending from .000 to .088 . The chisquare statistic is also acceptable $(P=.15)$. These measures suggest that the model has a correct fit. That is, the hypotheses constraining the parsimonious model comply with the observed phenomena. Moreover, as indicated by the $R^{2}$ of the performance equation, the parsimonious model predicts $40 \%$ of the relationship performance. Although $60 \%$ remains to be predicted, this can be considered a satisfactory result given the parsimony of the proposed model. Finally, it is noteworthy that the $t$-values of the parameters are significant at the $95 \%$ level of confidence (see Table 5). This suggests that a larger sample would result in higher significance levels.

In the final model (see Fig. 2), two main paths explain relationship performance. The first path, hereafter named relational coordination, contains the collective interest constructs of relationship experience, future orientation, commitment and trust. In this relational coordination path to performance, past relationship experience and the strength of future orientation to the relationship explain commitment $\left(R^{2}=.55\right)$, while commitment leads, either directly or via
443

444

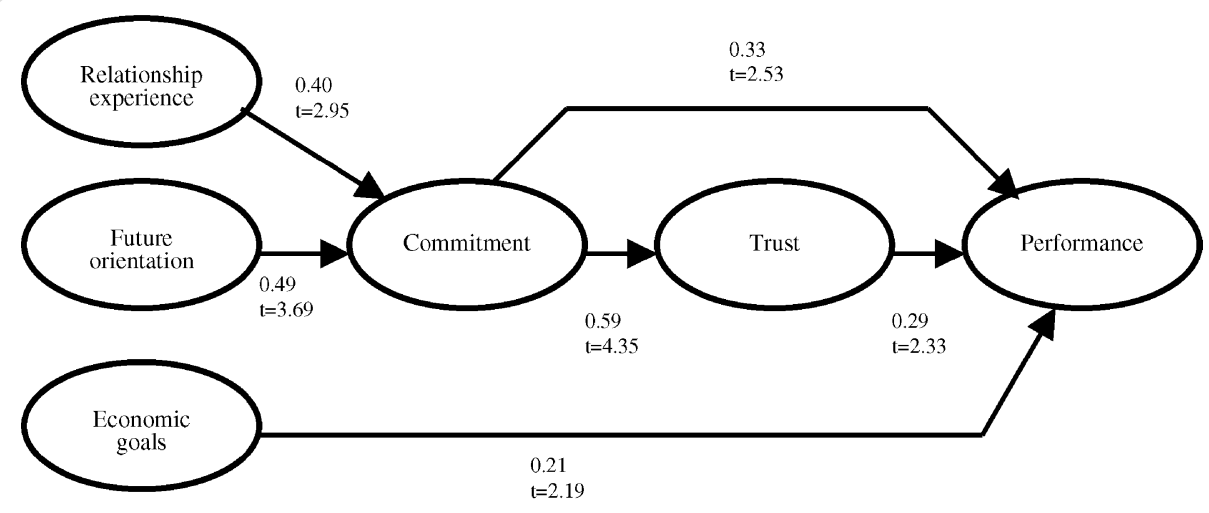

Fig. 2. Final paths. 
467 trust, to performance. In addition, future orientation is 468 slightly more important than past relationship experience 469 in explaining commitment $(\beta=.49$ and $\beta=.40$, respectively) 470 and in the indirect effects on trust (.29 and .24, respectively) 471 and performance (.25 and .20 , respectively).

472 The second path based on economic self-interest, hence473 forth-designated market coordination, contributes $18.6 \%$ to 474 the variance of performance according to the squared 475 parameters.

\section{Discussion and directions for future research}

There are five important, and related, conclusions to be drawn from these results. First, that a structural model was able to explain the associations between these constructs, given such a limited sample, suggests strongly that future study of coordination mechanisms should be conducted within realistic contexts, where the level of organization is explicitly included in the research. That is, coordination in a relationship results from inputs at the firm level and provides outputs at the next highest levels (i.e., relationship and network levels), such that relational coordination outputs must be measured as relationship performance in a network context.

Second, in this international context of the business software industry evidence was found of a strong influence of future oriented coordination, relationship experience, commitment, trust and a firm's economic goals on the performance of business relationships $\left(R^{2}=.40\right)$. This provides direct evidence, which strongly supports previous findings by Heide and John (1992), that relational coordination plays a significant role in explaining efficient relationships between firms. This result also supports the inclusion of only trust and commitment in the development of actor bonds as suggested by the IMP research (Håkansson and Snehota, 1995). This result means that future dyadic studies may concentrate on trust and commitment constructs, while the constructs of communication and conflict harmonization remain to be examined. On the other hand, this result raises the question of the role played by the remaining coordination constructs. One possibility is that the other coordination constructs play a role in explaining different performance dimensions, such as firm performance in relationships or contractual hierarchies (cf. Medlin, 2001).

Third, our empirical results support the view that relational coordination works in conjunction with self-interest (i.e., a firm's economic goals) to explain performance. That is, relational coordination constructs do not alone explain relationship performance; rather, they operate in combination with subsumed self-interest constructs to achieve performance. Further, this suggests that any analysis of business markets based merely on self-interest and economic constructs is reductive and flawed.

That economic goals do not explain more of relationship performance variance is an interesting result. To our know- ledge unreported to date, this observation is not commented upon previously in the literature. A number of possible explanations of the result may be postulated. First, it may be that the expectation component of the performance measure biases the construct towards a social measure and thus supports convergence of the relational coordination path. A second possibility relates to a deficiency of constructs in the market coordination path. This suggests that future research should look to include market coordination constructs, possibly based on firm use of resources and activities.

Fourth, in contrast to previous studies (Kalafatis and Miller, 1997; Morgan and Hunt, 1994), our results do not support the hypothesis of no causality from commitment to trust. This may be the result of using a composite level model or it may stem from the specific industry in which this study was conducted. For example, commitment to a principal or distributor in another country may be important for trust development, as firms are unlikely to have sufficient resources for more than one such relationship. In either case and in conjunction with previously reported research, our findings suggest that further research of relational coordination may be based upon interfirm trust and commitment.

Finally, this research needs to be repeated with a larger sample, as is evident from the need to remove constructs from analysis. In addition, while we argue that undertaking the study into one industry enhances considerably the internal validity of our results, we must acknowledge that they suffer from a commensurate lack of external validity and we cannot generalise the model proposed in Fig. 2 as representing relationships operating in other industrial sectors.

That communication and conflict harmonization could not be operationalized as unidimensional constructs indicates a need for further theoretical elaboration that can lead to improved measurement. Moreover, role integrity and flexibility appeared to have limited applicability in this study. Whether this is related to the specific sample or the symptom of a lack in theory development, it clearly requires further research. It is possible that measures of role integrity based on deeper theoretical development may be required, while flexibility may be construed as either acquiescence or use of influence indicating the need for further theory development.

In conclusion, there are two important results from this research. First, apart from the unresolved issues of how communication and conflict harmonization are implicated in relational coordination, future dyadic studies seeking to explain relationship performance need only concentrate on explaining how trust and commitment are involved in efficient resource and activity allocation across a dyad. This is important as it reduces the burden of future research. Second, and more importantly, this research shows how composite models, across different levels of organization, may be used to examine process related constructs in an appropriate context. Furthermore, this opens the way to dyadic studies based on complementary measures of relationship performance. 


\section{References}

Achrol RS. Changes in the theory of interorganizational relations in marketing: toward a network paradigm. J Acad Mark Sci 1997;25(1): $56-71$.

Akiake H. Factor analysis and AIC. Psychometrika 1987;52:317-32.

Anderson JC, Narus JA. Towards a better understanding of distribution channel working relationships. In: Backhaus K, Wilson D, editors. Industrial marketing: a German-American perspective. Berlin: SpringerVerlag; 1986. p. 320-36.

Axelsson B, Easton G. Industrial networks: a new view of reality; 1992.

Bonoma T. Conflict, cooperation and trust in three power systems. Behav Sci 1976;21:499-514 [November].

Bonoma T, Bagozzi R, Zaltman G. The dyadic paradigm with specific application toward industrial marketing. In: Bonoma T, Zaltman G, editors. Organizational buying behaviour. Chicago, IL: American Marketing Association; 1978. p. 49-66.

Borys B, Jemison DB. Hybrid arrangements as strategic alliances: theoretical issues in organisational combinations. Acad Manage Rev 1989; 14(2):234-49.

Boyle B, Dwyer FR, Robicheaux RA, Simpson JT. Influence strategies in marketing channels: measures and use in different relationship structures. J Mark Res 1992;XXIX:462-73 [November].

Bozdogan H. Model selection and Akaike's Information Criterion (AIC). Psychometrika 1987;52:345-70.

Bradach JL, Eccles RG. Price, authority, and trust: from ideal types to plural forms. Annu Rev Sociol 1989;15:97-118.

Brown JR. Channel cooperation: its relationship to channel performance. In: Lusch RF, Zinszer PH, editors. Contemporary issues in marketing channels, Center for Economics and Management Research. University of Oklahoma; 1979. p. 87-101.

Campbell DT. The informant in quantitative research. Am J Sociol 1955;60:339-43 [January].

Chan D. Functional relations among constructs in the same content domain at different levels of analysis: a typology of composition models. J Appl Psychol 1998;83:234-46.

Dwyer RF, Schurr PH, Oh S. Developing buyer-seller relationships. J Mark 1987;51:11-27 [April].

Elias N. The symbol theory. SAGE Publications; 1991.

Ford D. Understanding business markets: interaction, relationships and networks. San Diego, CA: Academic Press; 1990.

Frazier GL. Organizing and managing channels of distribution. J Acad Mark Sci 1999;27(2):226-40.

Gaski JF. The theory of power and conflict in channels of distribution. J Mark 1984;48:9-29 [Summer].

Gaski JF. Interrelations among a channel entity's power sources: impact of the exercise of reward and coercion on expert, referent, and legitimate power sources. J Mark Res 1986;XXIII:62-77 [February]

Giddens A. Central problems in social theory: action, structure and contradiction in social analysis. Berkley, CA: University of California Press; 1979.

Gundlach GT, Achrol RS, Mentzer JT. The structure of commitment in exchange. J Mark 1995;59:78-92 [January].

Håkansson H. International marketing and purchasing of industrial goods. Chichester: Wiley; 1982.
Håkansson H, Snehota I. Developing relationships in business networks. London: International Thomson Business Press; 1995.

Heide JB, John G. Do norms matter in marketing relationships? J Mark 1992;56:32-44 [April].

Jöreskog KG, Sörbom D. Lisrel VIII. Chicago: SSI; 1996.

Kalafatis SP, Miller H. A re-examination of the commitment-trust theory. In: Gemunden HG, Ritter T, Walter A, editors. Relationships and networks in international markets. Pergamon; 1997. p. 213-27.

Kaplan D. Evaluating and modifying covariance structure models. Multivariate Behav. Res. 1990;25(2):137-55.

Kaufmann PJ, Stern LW. Relational exchange norms, perceptions of unfairness, and retained hostility in commercial litigation. J Conflict Resol 1988;32:534-52 [September].

Loehlin JC. Latent variable models: an introduction to factor, path and structural analysis. Hillsdale, NJ: Erlbaum; 1992.

Lumpkin GT, Dess GG. Clarifying the entrepreneurial orientation construct and linking it to performance. Acad Manage Rev 1996;21(1):135-72.

Macneil IR. The many futures of contracts. South Calif Law Rev 1974;47: 691-816.

Macneil IR. Contracts: adjustment of long-term economic relations under classical, neo-classical and relational contract law. Northwestern Univ Law Rev 1978;72(1978):854-906.

Macneil IR. The new social contract: an inquiry into modern contractual relations. New Haven: Yale Univ. Press; 1980.

Macneil IR. Values in contracts. Northwestern Univ. Law Rev. 1983; 78:340-418 [April]

Macneil IR. Relational contract: what we do and do not know. Wisconsin Law Rev 1985;483-525.

Medlin CJ. Interaction possibility space: contextual shifts, actor bonds, and dyadic studies. 17th ed. IMP, 2001.

Medlin CJ, Quester PG. Actor bonds and relational norms in networks. 15th Annual IMP Conference, 1999.

Morgan RM, Hunt SD. The commitment-trust theory of relationship marketing. J Mark 1994;58:20-38 [July].

Morgeson FP, Hofman DA. The structure and function of collective constructs: implications for multilevel research and theory development. Acad Manage Rev 1999;24(2):249-65.

Rosenberg LL, Stern LW. Conflict measurement in the distribution channel. J Mark Res 1971;8:437-42 [November].

Rousseau DM. Issues of level in organizational research. In: Cummings LL, Staw BM, editors. Research in organizational behavior, vol. 7. Greenwich, CT: JAI Press; 1985. p. 1-37.

Steiger JH. EzPATH: causal modeling. Evanston, IL: SYSTAT, 1989.

Weitz BA, Jap SD. Relationship marketing and distribution channels. J Acad Mark Sci 1995;23(4):305-20.

Wilkinson IF. Power and influence structures in distribution channels. Eur J Mark 1973;7(2):119-29.

Wilson DT. An integrated model of buyer-seller relationships. J Acad Mark Sci 1995;23(4):335-46.

Young LC, Wilkinson IF. The space between: towards a typology of interfirm relations. J Bus-Bus Mark 1997;4(2):53-97.

Zaheer A, Venkatraman N. Relational governance as an interorganizational strategy: an empirical test of the role of trust in economic exchange. Strateg Manage J 1995;16:373-92. 